\title{
А.И. Фролов
}

\section{АКЦЕССОРНОСТЬ КАК ЭФФЕКТ ФУНКЦИОНАЛЬНОЙ ПРОИЗВОДНОСТИ ГРАЖДАНСКОГО ПРАВООТНОШЕНИЯ}

\begin{abstract}
Представлен теоретический очерк проблемы понятия «акиессорность» в гражданском праве. Дается критическая оценка постулатов господствующей доктрины акцессорности. Аргументированно оспариваются теории, отождествляющие акиессорное обязательство с обеспечительным обязательством. Акцессорность рассматривается как вторичное свойство, обусловленное функииональной связью правоотношений, как проявление функииональной производности правоотношения. Проводится соотношение свойства акиессорности правоотношения со свойством его функииональной производности.

Ключевые слова: акцессорность, акцессорное обязательство, обеспечительное обязательство, способы обеспечения исполнения обязательств, деривативное обязательство.
\end{abstract}

В общепринятом понимании акцессорное обязательство является таким обязательством, которое существует только наряду с другим, основным обязательством. Вместе с тем гораздо большее значение имеет вопрос о том, в силу каких причин одно из обязательств не может существовать без другого. Традиционная доктрина акцессорности не может дать адекватный ответ на этот вопрос, несмотря на очевидные проблемы при толковании понятия акцессорности. К решению проблемы необходимо подходить, исходя того факта, что свойством акцессорности обладают не только обеспечительные обязательства и не только обязательства вообще. Акцессорность - понятие межинституциональное. Для обеспечения тождества понятия «акцессорность», его единообразного применения к различным правовым институтам нельзя его расширять и видоизменять в зависимости от особенностей конкретной правовой конструкции.

Одной из проблем современного понятия «акиессорность» следует отметить неоправданное расширение объема понятия. Акцессорность как цивилистическая категория прошла длительный путь своего развития. В римском праве акцессорное обязательство рассматривалось как обязательство, существование которого обусловливалось наличием основного обязательства. В связи с особенностями хозяйственного оборота древнего общества понятие акцессорного обязательства римского права не может в полной мере соответствовать потребностям современного общества в регулировании товарно-денежных отношений. Поэтому искать истину, 
основываясь только на текстах древних, - не лучший путь. Однако учет генетического кода акцессорности позволит точнее определить ее природу.

Сохранившиеся источники римского права не обнаруживают признаков глубоко и детально разработанной теории акцессорности. Доктрина акцессорности сформировалась позднее, глоссаторами [1. Р. 121-122]. Однако первоначальная идея была достаточно простой и лаконичной.

Акцессорность изначально в римском праве предполагала дополнительность к основному обязательству. Дополнительность сама по себе могла означать только одно. Известная цитата из Дигест Ульпиана (In omnibus speciebus liberationum etiam accessiones liberantur, puta adpromissores hypothecate pignora) в переводе означает, что с прекращением основного обязательства прекращаются и дополнительные обязательства. Только в этом и заключалась первоначальная идея акцессорности: нет основного обязательства - нет дополнительного. Это означает, что акцессорность свойство одностороннего эффекта. Обратного влияния акцессорного обязательства на главное не возникает.

В последующем (в основном стараниями германских пандектистов XIX в.) первоначальная концепция акцессорного обязательства претерпела существенные изменения. Можно сказать, что теория акцессорного обязательства свернула с верного пути развития. Главный упрек исследователям того времени - смешение акцессорного обязательства и обеспечительного. В подавляющем большинстве исследований акцессорные обязательства раскрываются через призму обеспечительных обязательств. Не удивительно, что по мере усложнения гражданского оборота первоначальная идея акцессорности (дополнительности) не смогла удовлетворять обеспечительные обязательства. Понятие акцессорного обязательства расширилось за счет таких признаков, как свойство следования за основным обязательством, свойство зависимости акцессорного обязательства от изменения объема основного, свойство зависимости акцессорного обязательства от возможностей принудительной реализации основного обязательства.

Изначальная «дополнительность», предполагающая свойство одностороннего эффекта главного обязательства на акцессорное, трансформировалась в свойство двустороннего эффекта, когда акцессорное обязательство отражается на главном. Например, невозможность реализации главного обязательства как основание прекращения (или невозможности принудительного осуществления) акцессорного предопределяется интересами должника по акцессорному обязательству, который не получает возможности занять место кредитора в основном обязательстве по выплате долга. То же самое происходит и при зависимости акцессорного обязательства от изменения объема основного требования и уступке обеспеченного права: принимаются во внимание интересы должника в акцессорном обязательстве.

Другой проблемой понятия «акиессорность» является отождествление акиессорного юридического отношения с обеспечительным обязательством. В римском праве, а вслед за ним и в континентальном праве, на протяжении всего периода его развития акцессорность рассматривается 
в основном в контексте обязательств, обеспечивающих возврат долга. Однако с развитием оборота и усложнением права появились примеры акцессорных правоотношений иного рода, не связанных с обеспечительными обязательствами. Например, акцессорное обязательство по уплате процентов, не имеющее обеспечительного характера [2. С. 76].

Список видов акцессорных отношений можно продолжить. Акцессорными являются субправа (субаренда, субподряд, субкомиссия и др.). Акцессорно обязательство по передаче принадлежности к товару. Акцессорность как понятие идейно ближе к обязательственному праву. Однако примеры акцессорных отношений можно обнаружить во многих институтах гражданского права. Звучит несколько необычно, но акцессорны ограниченные вещные права: они существуют, пока существует право собственности на вещь (неважно, у кого именно). Акцессорны исключительные имущественные права автора произведения, поскольку с прекращением авторского права прекращаются исключительные права.

В научном обороте укоренилось отождествление акцессорного обязательства с обеспечительным. Наиболее радикальная позиция сводится к полному отождествлению терминов «обеспечительное» и «акцессорное» обязательство [3. С. 683, 685]. Другие исследователи рассматривают акцессорность как непременный признак обеспечительных обязательств [4]. При этом иные явно обеспечительные обязательства (например, независимая гарантия), которые не обладают акцессорностью, выводят за рамки обеспечительных [5].

Проблема усугубляется отсутствием у акцессорности в общепринятом ее понимании терминологической чистоты. Свойством акцессорности обладают разные типы обязательств (да и вообще юридических отношений). Каждый из типов обязательств имеет свои характерные черты. Отдельные виды обеспечительных обязательств в своей группе также обладают спецификой. Учитывая сказанное ранее о расширении признаков акцессорности, будет проблематично сохранить внутреннее тождество понятия «акцессорное отношение». В зависимости от признаков конкретного правоотношения, наделяемого свойством акцессорности, мы будем вынуждены констатировать, что акцессорность в одном случае - это одно, а в другом случае нечто иное.

В соответствии с широким подходом акцессорность наполняется различным содержанием при определении ее на различных этапах динамики обязательства: акцессорность возникновения, акцессорность прекращения, акцессорность следования (уступка основного обязательства влечет переход прав по акцессорному), акцессорность объема (объем основного долга предопределяет объем акцессорного), акцессорность принудительного осуществления основного обязательства (возражения должника по основному обязательству могут быть противопоставлены кредитору по обеспечительному) [6. S. 499; 7. P. 7; 8]. Уже с первого взгляда ясно, что предметом такой теории является не простая дополнительность, а сложная взаимосвязь между обязательствами. Выходит, что для каждого из обязательств 
(речь пока только об обеспечительных акцессорных обязательствах!) существует собственная (особенная) акцессорность, наполненная различными признаками. Если так, то происходит подмена единого понятия «акцессорность» различными в своих признаках понятиями, обозначаемыми одним термином. Такой подход сложно назвать научным.

Акцессорность как понятие общецивилистическое требует простоты и постоянства в своем объеме. В этой связи заслуживает поддержки узкий подход к пониманию акцессорности, в соответствии с которым акцессорность означает лишь то, что обязательство не может возникнуть или существовать, если основное обязательство не возникло или не существует, а также что прекращение основного обязательства влечет прекращение акцессорного [9. С. 55].

При таком подходе понятие акцессорности не девальвируется. Что касается иных аспектов межобязательственных связей, то они должны объясняться не в связи с акцессорностью, а в контексте функциональной нагрузки соответствующего обязательства.

Функииональный подход к анализу свойства акиессорности обнаруживает вторичность свойства акиессорности по отношению к свойству функииональной производности правоотношения. Непринятие цивилистами того обстоятельства, что акцессорность не ограничивается только сферой обеспечительных обязательств (как и обязательств вообще), а также недооценка того факта, что обеспечительные обязательства обладают иными свойствами, кроме акцессорности, привело к ошибкам. Во-первых, произошло смешение понятий «акцессорное обязательство» и «обеспечительное обязательство». Во-вторых, первоначальное понятие «акцессорное обязательство» (т.е. обязательство, действительное только при действительности основного обязательства) наполнилось иным смыслом и стало охватывать иные взаимосвязи между обязательствами.

Методологически верным представляется подход к исследованию различных правовых феноменов в их взаимосвязи и с учетом обусловленного этой взаимосвязью места в правовой системе [10. С. 434-437].

Функциональный подход позволяет акцентироваться на назначении (служебной роли) тех или иных правовых явлений в их взаимосвязи с другими правовыми явлениями. Акцессорность через эту призму раскрывается иначе.

Акцессорность никогда не появляется на пустом месте. Она - следствие связи между правоотношениями, например между обеспечиваемым и обеспечительным обязательствами. Вместе с тем также важно учитывать, что акцессорность не является единственно возможной формой связи между этими же гражданско-правовыми отношениями. Более того, акцессорность сама по себе является следствием иной, базовой связи между обязательствами и в этом смысле вторична.

Нам близка позиция немецких цивилистов, разработавших концепцию «обеспечительной цели» (Sicherungszweck), которая противопоставляется акцессорности обеспечительного обязательства, а при противоречии между акцессорностью и обеспечительной целью приоритет имеет по- 
следняя [6. S. 499; 11. S. 1817; 12. S. 75-129]. Концепция «обеспечительной цели» позволяет акцентировать внимание на назначении обеспечительного обязательства и при наличии формальных оснований прекращения обеспечительного обязательства в связи с акцессорностью по возможности сохранить его в силе. Например, при изменении размера долга не прекращать поручительство, а только ограничить ответственность поручителя суммой первоначального долга (п. 2 ст. 367 ГК РФ).

Абстрагируясь от сказанного выше, следует заметить, что существуют различные формы связи между гражданскими правоотношениями. Ряд связей обусловлен происхождением одних отношений от других, когда правоотношение выступает юридическим фактом или предпосылкой возникновения иного правоотношения, например при возникновении охранительного обязательства в случае нарушения регулятивного обязательства. В других случаях правоотношение может стать базой для установления на его основе другого правоотношения, как в случае связи между арендной и субарендой.

Юридические связи правоотношений имеют существенное значение, что дает основание для обособления их в особую группу производных, или деривативных, юридических отношений (от лат. derivo - отводить, проводить, derivari - происходить, проистекать, derivativus - производный, произведенный) [13]. Деривативные правоотношения можно подразделить на два типа. Первый тип - конститутивно-производные, которые образованы на «правовой материи» базового отношения (к примеру, субобязательства: субподряд, субкомиссия и т.д.). Они обладают свойством акцессорности и не могут квалифицироваться в качестве действительных при недействительности базового правоотношения. Второй тип - функциональнопроизводные правоотношения, которые связаны с базовым юридическим отношением только функцией, своим предназначением (к примеру, соглашение о возмещении потерь (ст. 406.1 ГК РФ) или соглашение об опционе (ст. 429.2 ГК РФ)). Второй тип деривативных правоотношений не всегда обладает свойством акцессорности. Но при этом обнаруживается иная юридическая связь: функционально-производная связь между правоотношениями, при которой функции деривативного правоотношения детерминируются базовым правоотношением.

Например, соглашение об опционе не может быть акцессорным, так как в соответствии с законодательно зафиксированной моделью этого соглашения возникновение базового обязательства является факультативной стадией. Отношения сторон могут ограничиться только тем, что адресат безотзывной оферты оплачивает оференту ее предоставление, что также выступает юридически отличимым опционным обязательством, которое является деривативным от базового обязательства (планировавшиеся купля-продажа, подряд и т.д.). Акцепт оферты и возникновение базового обязательства целиком зависят от лица, которому предоставлен опцион.

Также известны примеры неакцессорных обеспечительных обязательств. В первом ряду - независимая гарантия, которую следует относить к деривативным обязательствам второго типа. Абстрактное вексельное 
обязательство также немыслимо в костюме акцессорности. При этом как независимая гарантия, так и вексель возникают не на пустом месте и не просто так. Они функционально связаны с обеспеченным долгом и отношениями покрытия соответственно. Эта связь также имеет юридическое значение, что находит подтверждение в судебной практике в виде отказа в реализации права недобросовестного векселедержателя и бенефициара по гарантии (п. 4 Информационного письма Президиума ВАС РФ от 15.01.1998 № 27 «Обзор практики разрешения споров, связанных с применением норм Гражданского кодекса Российской Федерации о банковской гарантии»; п. 15 Постановления Пленума ВС РФ и ВАС РФ № 33/14 от 04.12.2000 «О некоторых вопросах практики рассмотрения споров, связанных с обращением векселей»; Определение ВС РФ от 08.12.2014 № 305-ЭС14-4754 по делу № А40-63311/12; Определение ВС РФ от 27.08.2015 № 305-ЭС15-9585 по делу № А-40-122484/2014).

Можно заметить, что, даже в случае отсутствия акцессорности, юридическая связь между обязательствами не исключается.

К какому типу деривативного правоотношения следует относить акцессорное обязательство? Ответ - ни к какому. Акцессорных обязательств как особого типа обязательств (ценного самого по себе) вообще не существует! Но это ни в коем случае не отрицает существования акцессорности как свойства (как признака) того или иного правоотношения. Термин «акцессорное обязательство» приобретает условный характер, но может использоваться, исходя из соображений утилитарного удобства и по устоявшейся традиции.

При этом следует учитывать, что свойство акцессорности заключает одностороннюю зависимость юридического отношения от другого (основного) и не допускает взаимозависимости [14. S. 117]. Кроме того, наделение правоотношения свойством акцессорности объясняется особым конститутивно-зависимым положением правоотношения (субаренда, право хозяйственного ведения) или его функциональным назначением (различным в зависимости от вида правоотношения, типа обязательства, его цели и т.д.).

Акцессорность, обусловленная конститутивной зависимостью правоотношения, в настоящей статье не рассматривается, поскольку в силу исследованности упомянутых правоотношений существенной проблематики не составляет, чего нельзя сказать о функционально-обусловленной акцессорности.

Акцессорность как свойство зачастую сочетается с первичным свойством деривативности (функциональной производности) юридического отношения. К примеру, назначение обеспечительного обязательства состоит в создании большей вероятности исполнения основного обязательства (обеспечиваемого), покрытии риска кредитора в неисполнении обязательства. По этой причине обеспечительное обязательство следует рассматривать в качестве деривативного. Наделение обеспечительного обязательства свойством акцессорности следует за деривативной природой такого обязательства, предопределенной функциональной связью с обеспечиваемым базовым обязательством. По функциональному критерию обеспечительные 
обязательства следует относить к деривативным обязательствам второго типа (функционально-производным).

Подход к акцессорности как к функциональной дополнительности [15. C. 518] или функциональной зависимости [5] представляется ошибочным. Свойство акцессорности, взятое само по себе, не обладает целевой направленностью. Акцессорность предопределяется присущей конкретному обязательству функцией. Обязательство наделяется свойством акцессорности, когда этого требует его производная (деривативная) природа. В отношении конститутивно-обусловленной акцессорности выделение функциональности вовсе может не являться юридически значимым.

Акцессорность с учетом изложенного можно рассматривать в качестве одного из возможных эффектов функциональной производности гражданского правоотношения.

Под акцессорностью следует понимать обусловленное функциональнопроизводной связью (или конститутивной производностью) правоотношений свойство односторонней зависимости одного правоотношения от другого и выражается в формуле древних: действительность акцессорного правоотношения предопределена действительностью основного правоотношения.

Несовершенство теории акиессорности становится причиной практических проблем акцессорности обеспечительного обязательства. Принимая во внимание отмеченное ранее, современная теория акцессорного обязательства не способна решить множество практических проблем.

Одну из таких проблем порождает широкое понимание акцессорности, вбирающее все варианты связи между обязательствами, кроме дополнительности как таковой. Судебная практика на основе акцессорности с «успехом» прекращает или признает отсутствующими обеспечительные обязательства, когда это совсем не является вынужденной мерой. Когда требуется точная настройка отношений, акцессорность стремится вместо настройки «убить» акцессорное обязательство.

Другая проблема практики заключается в механическом, формальном применении доктрины акцессорности. Однако избежать формализма можно только посредством внедрения в практику гибких инструментов. Акцессорность не может быть гибкой, как бы этого ни хотелось многим современным авторам [8]. Акцессорность, как «да» или «нет», не допускает иного: недействительно основное - недействительно акцессорное.

Еще совсем недавно проблема существовала особенно выпукло. Например, ранее суды аннулировали акцессорные обеспечительные обязательства при малейшем изменении обеспеченного обязательства, не признавали последствий за сделкой, направленной на установление обеспечения, при ее совершении до сделки-основания основного обязательства (Постановление ФАС Западно-Сибирского округа от 18 февраля 2003 г. № Ф04/643-63/А67-2003; Постановление ФАС Северо-Западного округа от 12 мая 2003 г. № А56-25885/02; Постановление ФАС Уральского округа от 14 августа 2006 г. № Ф09-6885/06-С5 по делу N A50-4619/06). 
Произошедшие изменения в судебной практике (Постановление Пленума ВАС РФ от 17 февраля 2011 г. № 10 «О некоторых вопросах применения законодательства о залоге»; Постановление Пленума ВАС РФ от 12 июля 2012 г. № 42 «О некоторых вопросах разрешения споров, связанных с поручительством»), а также новеллы ГК РФ (например, п. 2 ст. 336, пп. 1, 2 ст. 339 , п. 2 ст. 353 , ст. 355 в редакции Ф3 № 367 от 21.12 .2013 ; пп. 1, 3 ст. 361 , п. 4 ст. 363 , ст. 367 ГК РФ в ред. Ф3 № 42 от 08.03.2015) существенно ослабили жесткий подход к акцессорности. Это, конечно, сгладило проблему для практики, но усложнило ее в теоретическом отношении.

К сожалению, эти изменения опираются скорее не на хорошую теорию, а на требования бизнеса, особенно крупного банковского, голос которого слышен сильнее других. В действительности мы наблюдаем отсутствие точного понятийного аппарата, что, несомненно, способно повлечь ошибки на практике. Правоприменитель вынужден действовать вслепую, не зная о том, что же такое акцессорность, вынося решение по интуиции. Отход от прежних позиций стопроцентной акцессорности, снижение акцессорности выводит на авансцену обязательства, «почти» акцессорные или частично акцессорные, что не добавляет стабильности гражданскому обороту.

Объяснение природы акцессорности через понимание ее как эффекта функциональной производности соответствующего правоотношения позволяет обеспечить надлежащую настройку взаимосвязи между акцессорным и основным правоотношениями.

Как, например, традиционная доктрина акцессорности способна объяснить, что при заключении мирового соглашения с кредиторами основного должника и уменьшении суммы долга основного должника требование к поручителю (или залогодателю, не являющемуся должником по основному долгу) сохраняется в прежнем объеме? Такое решение принял Верховный Суд РФ (Определение Судебной коллегии по экономическим спорам ВС РФ от 14.06.2016 № 308-ЭС16-1443). Не будем делать выводы о верности такого решения, но очевидно, что высшая судебная инстанция поддержала обеспечительную цель (функцию) вопреки акцессорности.

Заслужсивает отдельного внимания вопрос снижения акцессорности обеспечительных обязательств. Мнение о потребности современного оборота в снижении акцессорности обеспечительных обязательств и появлении новых, неакцессорных вовсе, набирает сторонников.

Однако свойство акцессорности не может снижаться или расширяться, оно или есть, или его нет. В широком понимании акцессорность не может представлять собой что-то единое. А в правильном, на наш взгляд, узком понимании теория акцессорности не позволяет объяснить все связи между обязательствами.

Например, свойство акцессорности не годится в деле определения последствий увеличения основного долга по отношению к обеспечительному обязательству. Как дополнительность сама по себе зависит от величины долга и от его изменения? Конструкция дополнительного отношения допускает существование отношений, не зависящих от изменения основного 
отношения. Например, при увеличении арендной платы субарендное отношение не прекращается и не изменяется. В соответствии с новеллой ст. 367 ГК РФ при увеличении основного долга поручительство сохраняется на прежних условиях. Это решение принято с учетом функциональной связи поручительства с долгом, а не в связи его акцессорностью. Обеспечительное обязательство, выступая гарантией исполнения основного обязательства, не является при этом способом переложения неограниченной ответственности на поручителя.

Акцессорность не может дать ответ на вопрос, следует ли обеспечительное обязательство вслед за обеспечиваемым, поскольку свойство акцессорности (суть только зависимость действительности обеспечительного обязательства) не может объяснить вопросы правопреемства. При переходе прав по обеспеченному обязательству последнее не прекращается, следовательно, нет оснований для прекращения обеспечительных обязательств. Тот факт, что в этом случае утрачивается смысл обеспечительных обязательств и что-то с этим нужно делать, объясняется не свойством акцессорности, а функциональным назначением обеспечительного обязательства. Кредиторы в основном и обеспечительном обязательстве должны совпадать. Только в этом случае выполняется функция обеспечения интересов кредитора (а не иного лица) на получение исполнения, а также устраняется возможность оплаты должником дважды по одному долгу. Однако в интеpecax оборота возможно разделение обеспеченного обязательства и обеспечительного (например, залога на основании п. 2 ст. 354 и ст. 355 ГК РФ).

Акцессорность как односторонняя зависимость правоотношения (например, обеспечительного обязательства) от действительности основного (например, обеспеченного обязательства) на поверку оказывается непригодным инструментом, когда необходимо принять во внимание и учесть интересы должника в акцессорном обязательстве, т.е. когда акцессорное обязательство оказывает обратное действие на основное обязательство.

Кроме того, представляется, что наблюдаемое снижение акцессорности обеспечительных обязательств (например, залог, поручительство) в интеpecax оборота не должно (да и не может) приводить к полной утрате связанности обязательств. Но связь эта иная - функционально-производная.

Свойство функииональной деривативности следует рассматривать как стержень конструкиии обеспечительного обязательства. В отношении обеспечительных обязательств следует сделать вывод, что только имманентная функциональная связь обеспечиваемого и обеспечительного обязательств должна быть стержнем конструкции обеспечительных обязательств, а не акцессорность. В настоящее время по причинам, изложенным выше, проблематика обеспечительных обязательств построена на акцессорности.

Свойство функциональной деривативности позволяет провести точную настройку и ответить на вопросы о судьбе зависимого обязательства в случае, когда базовое отношение сохраняется в силе, но меняются условия его осуществления. 
На основе функционального подхода можно ответить на вопросы, неразрешимые в парадигме акцессорности. При изменении объема главного отношения нет необходимости в прекращении обеспечительного (деривативного), если это не противоречит функции последнего. Правило следования прав по обеспечительному обязательству основано на функциональной связи этого обязательства с базовым отношением. Переход прав по обеспечительному обязательству без перехода прав по обеспеченному обязательству в принципе возможен, но не может приводить к утрате функциональной ценности обеспечения. Трудности с принудительной реализацией основного обязательства могут отражаться на судьбе обеспечительного, если это также в конкретном случае не противоречит деривативной сущности обеспечительного обязательства. Возможность или невозможность должника в обеспечительном обязательстве приводить возражения должника по основному долгу вообще не связано с акцессорностью. Это обратное действие деривативного обязательства в отношении основного, предопределяемое функциональной связью обязательств, а не акцессорностью.

Не акцессорность, а свойство функциональной деривативности обеспечительного обязательства, предполагающее учет взаимной связи между обязательствами и взаимное же влияние их друг на друга (выполнение соответствующих функций), способно обеспечить должную гибкость правового регулирования способов обеспечения исполнения обязательств.

\section{Литература}

1. Zimmerman $R$. The Law of Obligations: Roman Foundations of the Civil Tradition. Cape Town : Juta, 1992. 1238 p.

2. Белов В.А. Гражданское право : в 4 т. М. : Юрайт. 2016. Т. 4, кн. 1.622 с.

3. Гражданское право : учебник / под ред. А.П. Сергеева, Ю.К. Толстого. 6-е изд. М. : Проспект, 2002. Т. 1.776 с.

4. Кулаков В.В. Акцессорность как признак способов обеспечения исполнения обязательств // Российский судья. 2006. № 6. С. 19-23.

5. Новиков К.А. Акцессорность обеспечительных обязательств и обеспечительноориентированные права // Вестник экономического правосудия. 2015. № 1. С. 107-120.

6. Medicus D. Durchblick: Die Akzessorietät im Zivilrecht // Juristische Schulung (JuS). 1971. S. 497-504

7. Steven A. Accessoriness and Security Over Land // University of Edinburgh School of Law Legal Studies Research Paper Series. № 2009/07. P. 387-426. URL: http://ssrn.com/ abstract $=1371139$

8. Бевзенко Р.С. Акцессорность обеспечительных обязательств. М. : Статут, 2013. 96 с.

9. Крашенинников E.A. К вопросу об изолированной уступке требования, обеспеченного поручительством // Очерки по торговому праву : сб. науч. трудов. Ярославль : Изд-во Яросл. ун-та, 2000. Вып. 7. С. 53-56.

10. Белов В.А. Гражданское право : в 4 т. М. : Юрайт, 2016. Т. 1.621 с.

11. Bettermann K. Akzessorietät und Sicherungszweck der Bürgschaft // Neue Juristische Wochenschrift (NJW). 1953. S. 1817. Цит. по: Шеломенцева Е.А. Понятие акцессорности обеспечительных обязательств в сравнительно-правовом аспекте // Вестник гражданского права. 2015. № 3. С. 57-105.

12. Eusterhus D. Die Akzessorietät im Bürgschaftsrecht : Eine Untersuchung zum deutschen und französischen Recht. München : Herbert Utz Verlag, 2002. 221 S. 
13. Фролов А.И. Концепция деривативного обязательства в гражданском праве // Закон. 2017. № 11. С. 193-202

14. Weber J-A. Die Haftung eintretender Gesellschafter für die Altverbindlichkeiten der Gesellschaft bürgerlichen Rechts. Frankfurt am Main, 2005. 294 S.

15. Дождев Д.В. Римское частное право / gод ред. проф. В.С. Нерсесянца. 5-е изд., изм. и доп. М. : ИНФРА-М, 2010. 783 с.

Frolov Alexey I., St. Petersburg law Institute of the Academy of the Prosecutor General of the Russian Federation (St. Petersburg, Russian Federation)

\section{ACCESSORITY AS AN EFFECT OF FUNCTIONAL DERIVATIVENESS OF CIVIL} LEGAL RELATIONSHIP

Keywords: accessority, accessory obligation, security obligation, ways of ensuring the performance of obligations, derivative obligation.

\section{DOI: $10.17223 / 22253513 / 29 / 18$}

In generally accepted understanding, the accessory obligation is the obligation, which exists only along with another obligation, the basic one. However, the question about the reasons due to which one obligation cannot exist without another is of great significance. A traditional doctrine of accessority cannot give the adequate answer to this question, despite obvious problems with the interpretation of a concept of accessority. It is necessary to solve the problem recognizing the fact that not only security obligations and not obligations in general have the property of accessority. Accessority is a cross-institutional concept. To ensure the identity of the concept "accessority" and its uniform application to various legal institutes, it is impossible to expand and alter it depending on the peculiarities of a definite legal construction.

One of the problems of a modern concept "accesority" is an unjustified expansion of volume of the concept. Accessority as a civil category had a long way of its development. In Roman law, the accessory obligation was considered an obligation the existence of which was caused by the presence of the main obligation. Due to the characteristics of economic turnover in ancient society, the concept of the accessory obligation in Roman law cannot correspond fully to the requirements of modern society in the sphere of regulation of commodity-money relations. Therefore, to look for the truth taking into account only ancient texts is not the best thing. However, a genetic code of accessority will enable us to define its nature more precisely.

The surviving sources of Roman law do not have signs of a deeply elaborated theory of accessority. The doctrine of accessority was created later, by glossators. However, the initial idea was rather simple and laconic.

In Roman law accessority initially assumed a complementarity to the main obligation. Complementarity itself could mean only one thing. The translation of a well-known quote from Digest Ulpian (In omnibus speciebus liberationum etiam accessiones liberantur, puta adpromissores hypothecate pignora) means that termination of the main obligation terminates additional obligations. Thus, the initial idea of accessority was: there is no additional obligation in the absence of the main one. It means that accessority is a property of a unilateral effect. The additional obligation has no reverse influence on the main one.

\section{References}

1. Zimmerman, R. (1992) The Law of Obligations: Roman Foundations of the Civil Tradition. Cape Town: Juta.

2. Belov, V.A. (2016) Grazhdanskoye pravo: $v 4$ t. [Civil Law: in 4 vols]. Vol. 4. Moscow: Yurayt.

3. Sergeyev, A.P. \& Tolstoy, Yu.K. (eds) (2002) Grazhdanskoye pravo [Civil Law]. 6th ed. Vol. 1. Moscow: Prospekt. 
4. Kulakov, V.V. (2006) Aktsessornost' kak priznak sposobov obespecheniya ispolneniya obyazatel'stv [Accessibility as a sign of ways to ensure the fulfillment of obligations]. Rossiyskiy sud'ya - Russian Judge. 6. pp. 19-23.

5. Novikov, K.A. (2015) Aktsessornost' obespechitel'nykh obyazatel'stv i obespechitel'nooriyentirovannyye prava [Accessory security obligations and security-oriented rights]. Vestnik ekonomicheskogo pravosudiya. 1. pp. 107-120.

6. Medicus, D. (1971) Durchblick: Die Akzessorietät im Zivilrecht [Perspective: The accessory law in civil law]. Juristische Schulung (JuS). pp. 497-504.

7. Steven, A. (2009) Accessoriness and Security Over Land. University of Edinburgh School of Law Legal Studies Research Paper Series. 2009/07. pp. 387-426. [Online] Available from: http://ssrn.com/ abstract=1371139. DOI: 10.3366/E1364980909000560

8. Bevzenko, R.S. (2013) Aktsessornost' obespechitel'nykh obyazatel'stv [Accessory security obligations]. Moscow: Statut.

9. Krasheninnikov, Ye.A. (2000) K voprosu ob izolirovannoy ustupke trebovaniya, obespechennogo poruchitel'stvom [On isolated assignment of the requirement guaranteed by a guarantee]. In: Krasheninnikov, Ye.A. (ed.) Ocherki po torgovomu pravu [Essays on Commercial Law]. Yaroslavl: Yaroslavl State University. pp. 53-56.

10. Belov, V.A. (2016) Grazhdanskoye pravo: $v 4$. [Civil Law: in 4 vols]. Vol. 1. Moscow: Yurayt.

11. Bettermann, K. (1953) Akzessorietät und Sicherungszweck der Bürgschaft [Accessory and purpose of the guarantee]. Neue Juristische Wochenschrift (NJW). pp. 1817. Cit. ex: Shelomentseva, Ye.A. (2015) Ponyatiye aktsessornosti obespechitel'nykh obyazatel'stv v sravnitel'no-pravovom aspekte [The concept of accessory security obligations in the comparative legal aspect]. Vestnik grazhdanskogo prava. 3. pp. 57-105.

12. Eusterhus, D. (2002) Die Akzessorietät im Bürgschaftsrecht: Eine Untersuchung zum deutschen und französischen Recht [The accessory law in the guarantee law: An investigation on German and French law]. Munich: Herbert Utz Verlag.

13. Frolov, A.I. (2017) Kontseptsiya derivativnogo obyazatel'stva v grazhdanskom prave [The concept of a derivative obligation in civil law]. Zakon. 11. pp. 193-202.

14. Weber, J-A. (2005) Die Haftung eintretender Gesellschafter für die Altverbindlichkeiten der Gesellschaft bürgerlichen Rechts [The liability of shareholders for the old liabilities of the company under civil law]. Frankfurt am Main: [s.n.].

15. Dozhdev, D.V. (2010) Rimskoye chastnoye pravo [Roman Private Law]. 5th ed. Moscow: INFRA-M. 